\title{
Descriptive norms for 350 Chinese idioms with seven syntactic structures
}

\author{
Degao $\mathrm{Li}^{1} \cdot$ Yu Zhang ${ }^{1} \cdot$ Xiaolu Wang ${ }^{1}$
}

Published online: 28 January 2016

(C) Psychonomic Society, Inc. 2016

\begin{abstract}
The most important forms of idioms in Chinese, chengyus (CYs), have a fixed length of four Chinese characters. Most CYs are joined structures of two, two-character words-subject-verb units (SVs), verb-object units (VOs), structures of modification (SMs), or verb-verb units - or of four, one-character words. Both the first and second pairs of words in a four-word CY form an SV, a VO, or an SM. In the present study, normative measures were obtained for knowledge, familiarity, subjective frequency, age of acquisition, predictability, literality, and compositionality for $350 \mathrm{CYs}$, and the influences of the CYs' syntactic structures on the descriptive norms were analyzed. Consistent with previous studies, all of the norms yielded a high reliability, and there were strong correlations between knowledge, familiarity, subjective frequency, and age of acquisition, and between familiarity and predictability. Unlike in previous studies (e.g., Libben \& Titone in Memory \& Cognition, 36, 1103-1121, 2008), however, we observed a strong correlation between literality and compositionality. In general, the results seem to support a hybrid view of idiom representation and comprehension. According to the evaluation scores, we further concluded that CYs consisting of just one SM are less likely to be decomposable than those with a VOVO composition, and also less likely to be recognized through their constituent words, or to be familiar to, known by, or encountered by users. CYs with an SMSM composition are less likely than VOVO CYs to be
\end{abstract}

Xiaolu Wang

lucywxl@zju.edu.cn

Degao Li

li-degao@163.com

1 Department of Linguistics, School of International Studies, Zhejiang University, Hangzhou, Zhejiang, People's Republic of China decomposable or to be known or encountered by users. Experimental studies should investigate how a CY's syntactic structure influences its representation and comprehension.

Keywords Chinese idioms · Descriptive norms $\cdot$ Syntactic structures

\section{Introduction}

Idioms are fixed expressions that are standardized in meaning and form. Some idioms (e.g., easy on the eyes) can be understood directly through the constituent words, but the overall meanings of other idioms (e.g., red herring) seem to have nothing to do with the conventional meanings of the words of which they are composed. Therefore, differences seem to exist among idioms in terms of how they are represented and how they are understood. Indeed, several theories have been proposed on this point. For example, idioms can be treated like complex words and be represented and understood as whole units (e.g., kick the bucket; see, e.g., Swinney \& Cutler, 1979). It is also argued that an idiom can receive different weights of contributions in representation from its constituent words (e.g., Gibbs \& Nayak, 1989) and cannot be understood without the semantic relations between its constituent words being processed (e.g., pop the question; e.g., Gibbs, Nayak, \& Cutting, 1989).

Recently, a hybrid view has begun to be well recognized; this theory assumes that idioms are both compositional and noncompositional. According to Cutting and Bock (1997), an idiom has its own representation of the lexical concept as a whole, the activation of which spreads to the representations for the constituent words at the lexical-syntactic (lemma) level. Sprenger, Levelt, and Kempen (2006) extended this theory, arguing that there are superlemmas between the representations for idioms as whole units and those for the constituent 
words. As separate representations for the syntactic properties of idioms, superlemmas are connected to the idioms' building blocks. As far as idiom comprehension is concerned, those that are predictable or familiar to the users are processed as whole units, but those that are not predictable or are unfamiliar to the users may have to be compositionally analyzed before being understood (Cacciari \& Tabossi, 1988; Titone \& Connine, 1999).

In fact, the characteristics of idioms, such as how familiar they are to the users and whether they are decomposable, seem to pertain to the development of theories of idiom representation and comprehension. It is even believed that norms such as those for the familiarity and compositionality of idioms could potentially be helpful for experimental studies into the cognitive mechanisms of how idiomatic expressions are represented and comprehended (see Bonin, Méot, \& Bugaiska, 2013, for a review), and several reports are available in this line of research (e.g., Bonin et al., 2013; Tabossi, Arduino, \& Fanari, 2011), in which the users' knowledge, familiarity, subjective frequency, and age of acquisition (AoA) of idioms, and the idioms' predictability, literality, and compositionality, are among the most important variables. By knowledge, we mean the degree to which the users think they know the overall meaning of an idiom and can verbally explain it (Tabossi et al., 2011). The more familiar a speaker is with an idiom, the more likely that he or she obtains access to its overall meaning via direct lookup (Cronk \& Schweigert, 1992). The subjective frequency of an idiom refers to how often users encounter it in everyday life (Bonin et al., 2013), and the AoA of an idiom is the age at which the users acquired it. By predictability, we mean the extent to which the users can complete an incomplete idiom, and by literality, we mean the degree to which the users think an idiom can be understood just through the literal meanings of its constituent words. The overall meanings of idioms of high predictability are retrieved more quickly than those of low predictability (Cacciari \& Tabossi, 1988). Because the processing of linguistic information is obligatory (Miller \& Johnson-Laird, 1976, as cited in Bonin et al., 2013), the literal meanings of an idiom's constituent words cannot be avoided. Compositionality refers to the degree to which the users think an idiom's overall meaning is composed of the meanings of its individual components. Decomposable idioms are different from noncompositional idioms in being understood by both children (Caillies \& Le Sourn-Bissaoui, 2008) and adults (Caillies \& Butcher, 2007).

For example, Tabossi et al. (2011) required 740 Italian speakers (ranging from 17 to 50 years in age) to participate in a study, and obtained descriptive norms for length, knowledge, familiarity, AoA, predictability, syntactic flexibility (the degree to which an idiom can be syntactically changed but still retain its overall meaning), literality, and compositionality for 245 idioms in Italian. By descriptive norms, we mean descriptive statistics for the idioms' features, obtained by means of objective measurements. Tabossi et al.'s discussions on the descriptive statistics of and the correlations between the variables are of significant value to empirical studies on Italian idioms. By collecting descriptive norms for knowledge, predictability, literality, compositionality, subjective and objective frequency, familiarity, AoA, and length for 305 French idioms, and measuring the comprehension times for these idioms, Bonin et al. (2013) demonstrated the rich relevance of norms for psycholinguistic studies on idiomatic expressions in French. Libben and Titone (2008) used both offline and online measures to analyze the normative characteristics of 219 English idioms. They found that high familiarity is associated with good comprehension, and that decomposability only plays a limited role in the early stages of idiom comprehension.

Each language has a large repertoire of idiomatic expressions (Cacciari \& Tabossi, 1988). To the authors' knowledge, however, few normative studies have reported on idioms in languages other than English (e.g., Cronk, Susan, Lima, \& Schweigert, 1993; Libben \& Titone, 2008; Titone \& Connine, 1994b), French (e.g., Bonin et al., 2013; Caillies, 2009), and Italian (e.g., Tabossi et al., 2011). The present study was performed to provide a normative description of Chinese idioms.

Unlike alphabetic languages, written Chinese has a logographic script in which the basic units are characters. Although many characters are words on their own, most can join with one or more than one character, to form twocharacter words or words of more than two characters. Actually, more than $70 \%$ of the 50,000 most frequently used words are two characters long (State Language Affairs Committee, 2008), and over $95 \%$ of Chinese idioms are of four characters (Liu \& Cheung, 2014). These four-character idioms are referred to as chengyus (CYs, hereafter).

One prominent feature of CYs is their fixed syntactic structures (Zhou, 2004). In $90 \%$ of cases, a CY has a syntactic structure of two, two-character words - a noun followed by a verb to form a subject-verb unit (SV; e.g., 泾渭不分, river Jing and river Wei-not separate), a verb followed by a noun to form a verb-object unit (VO; e.g., 渐入佳境, gradually enter into-a perfect condition), an adjective followed by a noun or an adverb followed by a verb to form a structure of modification (SM; e.g., 蔚然成风, luxuriantly-become a common practice), or a verb-verb unit (VV; e.g., 积劳成疾, accumulate labor-cause illness) - or of four one-character words. Both the first and second pairs of words in a four-word CY form an SV (e.g., 言简意赅, language-simple-meaningthoughtful), a VO (e.g., 扶危济㕅, help-those in danger-aidthose in peril), or an SM (e.g., 真才实学, genuine-talent-stur$d y$-knowledge). Since an idiom's syntactic structure plays a significant role in how it is represented and understood 
(Holsinger, 2013; Konopka \& Bock, 2009; Robert, Curt, Gary, \& Kathleen, 2001), an investigation into the relationship between CYs' syntactic structures and their descriptive norms will be helpful to provide indications of CYs' representation and comprehension. For example, are four-word CYs similar to two-word CYs in their correlations between the seven features? In what way are SM CYs different from SV CYs in literality? Answers to such questions can inspire a new understanding of how idioms are represented in general and can be of significant value to the designs of experimental studies into the mechanisms of idioms' representation and comprehension.

\section{Method}

\section{Participants}

The participants were 735 college students ( 385 males, 350 females; $M_{\text {age }}=18.9$ years, age range 18.2-20.3 years), who were recruited on campus by means of a flyer advertisement at a university in mainland China.

\section{Materials and procedure}

Inspired by Bonin et al. (2013), we recorded each measurement on a 7-point Likert scale. First, we roughly excluded those that might be unfamiliar to the participants from the 4, 227 CYs in the Normal Dictionary of Chinese Chengyu with Full Function (Chen, 2009; one of the most popular dictionaries of CYs in the country) that are SV, SM, VO, VV, SVSV, SMSM, or VOVO in structure. The CYs were divided into 39 groups at random. Ten college students were then required to evaluate the familiarity of the idioms in each group on a 3-point Likert scale ( 1 = unfamiliar, $2=$ familiar, 3 $=$ very familiar $)$. These students did not take part in the followup surveys. From the 3,694 CYs that had an average score of 2 or higher, 50 were selected at random for each of the seven syntactic structures.

Then, the $350 \mathrm{CYs}$ were mixed at random and divided into five equal groups. The CYs chosen for each of the groups can be found in the Appendix. Each group was printed on a sheet of paper in two columns with seven numbers ([1], [2], [3], [4], [5], [6], and [7]) at the right side of each CY. The instructions were printed at the top of the page. For each CY to be evaluated from the seven categories, the 735 participants were divided into 35 equal groups at random, and every one-piece-ofpaper questionnaire was delivered to a group of students, who were required to make an evaluation response to each $\mathrm{CY}$ according to the instructions by putting a tick in one of the seven numbers. Table 1 summarizes the instructions for the seven kinds of surveys.

\section{Results and discussion}

\section{The norms}

The descriptive statistics of the participants' responses on each questionnaire and the corresponding scores for reliability are displayed in Table 2.

As is shown in Table 2, all of the norms yielded a reliability score over.94. As in Bonin et al. (2013), the compositionality and AoA norms had the highest and lowest reliabilities, respectively. Moreover, the reliability score for the AoA norm was still very high $(\alpha=.941)$. Probably because the age range was wide for their participants, Tabossi et al. (2011) found that the AoA norm was significantly less reliable than their other norms. On the contrary, the high reliability scores across the seven scales in the present study seem to suggest a high degree of consistency among the college-student participants in their evaluations of the CYs.

The average evaluation scores for knowledge, familiarity, and predictability were quite high on the 7-point Likert scales. Furthermore, these three norms also had high absolute values of their skewness scores, suggesting that the participants were quite familiar with all the CYs, in agreement with Bonin et al. (2013). This was especially the case with the predictability norm $(6.52 \pm 0.57[M \pm S D])$. That is, the last character of a CY was very easy for the participants to predict, partly because of the expressions' fixed length of four characters. The low absolute values of the skewness scores suggest that the norms for literality, compositionality, and subjective frequency embrace symmetric distributions.

\section{Correlations}

The Pearson correlations between the scores of the participants' responses to each questionnaire were calculated, and the results are displayed in Table 3.

As is indicated in Table 3, the seven variables were significantly correlated with one another, but the correlations did not seem to be of the same strength. First, as in Bonin et al. (2013), there were strong intercorrelations between the participants' scores on knowledge, familiarity, subjective frequency, and AoA. That is, the earlier the participants acquired a CY, the more familiar they were with it, the more frequently they encountered it, and the more able they were to verbally explain it. Given that the effect of AoA is strong in tasks that require semantic code activation (e.g., Bonin, Barry, Méot, \& Chalard, 2004; Bonin et al., 2013; Johnston $\&$ Barry, 2006), we further speculate that the users' knowledge, familiarity, AoA, and subjective frequency of CYs might be strong indicators of semantic representations for CYs as wholes. 
Table 1 Questionnaire instructions

KNO Please decide the degree $(1=$ very low, $7=$ very high $)$ to which you think each CY is known by your peers and your peers can verbally explain it. The higher the number, the more likely you think your peers know its overall meaning and can verbally explain it.

FAM Please decide how familiar $(1=$ very unfamiliar, 7 = very familiar $)$ you are with each CY. The higher the number, the more familiar you are with it.

PRE Please decide the extent $(1=$ very small, $7=$ very large $)$ to which you can complete each CY if its last character is missing. The higher the number, the more likely you are able to complete it.

LIT Please decide the degree $(1=$ very low, $7=$ very high $)$ to which each CY means the same as its constituent words literally indicate. For example, the higher degree to which you think that 斩钉截铁 (cut-nails-cut-iron) and 走马观花 (ride-horse-view-flowers) mean “cut nails and cut iron" and "ride a horse and view flowers," respectively, the higher the corresponding number should be.

COM Please judge the extent $(1=$ very small, $7=$ very large $)$ to which the overall meaning of each CY is composed of the meanings of its individual components. The higher the number, the more you think that its constituent words contribute to its overall meaning.

SUB For each CY, please judge the frequency $(1=$ very low, $7=$ very high $)$ you hear, read, or speak it in daily life. The higher the number, the more often you encounter it in everyday life.

AoA For each CY, please indicate the time (the numbers 1, 2, 3, 4, 5, 6, and 7 refer to the ages of $8,10,12,14,16,18$, and 20, respectively) when you acquired it. The higher the number, the later you acquired it.

In all of the tables and in the figure, KNO, FAM, PRE, LIT, COM, SUB, and AoA indicate knowledge, familiarity, predictability, literality, compositionality, subjective frequency, and age of acquisition, respectively. VO, SM, SV, and VV refer to CYs whose two, two-character words form verb-object units, structures of modification, subject-verb units, and verb-verb units, respectively. And in VOVO, SMSM, and SVSV CYs, the first and second pairs of one-character words in the idiom both form VOs, SMs, and SVs, respectively

As in Titone and Connine (1994a) and Tabossi et al. (2011), the participants' evaluation scores for familiarity were strongly correlated with those of predictability, suggesting that the more familiar they were with a CY, the more likely they were to be able to complete it if its last character was missing. Consistent with this, the CYs' predictability was strongly correlated with the participants' knowledge, AoA, and subjective frequency of the CYs. This finding seems to be in support of Sprenger et al.'s (2006) theory that superlemmas mediate the connections between the conceptual representations for idioms as wholes and those for the component words. In other words, the users' familiarity and knowledge of CYs' overall meanings activate the superlemmas, which in turn help retrieve the component words.

Second, the participants' evaluation scores for literality were strongly correlated with those for compositionality, apparently contrary to the negative correlations between literality and compositionality in Libben and Titone (2008) and Bonin et al. (2013). In addition, Tabossi et al. (2011) found no correlation between literality and

Table 2 Statistics for all normed variables

\begin{tabular}{llllllll}
\hline & $M$ & $S D$ & Min & Max & Range & Skewness & $\alpha$ \\
\hline KNO & 6.04 & 0.58 & 3.71 & 6.88 & 3.17 & -1.23 & .968 \\
FAM & 5.87 & 0.58 & 3.45 & 6.80 & 3.35 & -1.12 & .976 \\
PRE & 6.52 & 0.57 & 2.90 & 7.00 & 4.10 & -2.91 & .962 \\
LIT & 5.17 & 0.76 & 2.71 & 6.76 & 4.05 & -0.64 & .963 \\
COM & 5.00 & 0.61 & 3.00 & 6.20 & 3.20 & -0.46 & .979 \\
SUB & 4.61 & 1.03 & 1.75 & 6.74 & 4.99 & -0.41 & .964 \\
AoA & 2.67 & 0.74 & 1.38 & 5.86 & 4.48 & 1.00 & .941 \\
\hline
\end{tabular}

compositionality. The difference between the present study and the previous studies (Bonin et al., 2013; Libben \& Titone, 2008; Tabossi et al., 2011) in terms of the correlations between literality and compositionality might be an indication of the specific nature of the Chinese written language. In Chinese, the meaning of an expression is more visually evident than in an alphabetic language (Zhang et al., 2013). The overall meaning of a CY is also likely to be induced through the meanings of its constituent words. Indeed, this result appears to be a piece of evidence in support of the superlemma theory, which predicts that the meanings of the constituent words predict production of the idiom (Sprenger et al., 2006).

Third, as in Tabossi et al. (2011), the participants' evaluation scores for familiarity and knowledge were strongly correlated with those for literality, indicating that college students' familiarity and knowledge of CYs are closely related to the literal meanings of the CYs' constituent words. Consistent with this finding, the participants' knowledge, AoA, and subjective frequency of CYs were significantly correlated with the CYs' literality and

Table 3 Correlation coefficient matrix

\begin{tabular}{|c|c|c|c|c|c|c|}
\hline & FAM & SUB & $\mathrm{AOA}$ & PRE & LIT & $\mathrm{COM}$ \\
\hline $\mathrm{KNO}$ & $.709^{* * * * *}$ & $.754^{* * * *}$ & $-.809^{* * * *}$ & $.603^{\text {**** }}$ & $.560^{* * *}$ & $.545^{* * * *}$ \\
\hline FAM & & $.733^{\text {**** }}$ & $-.687^{* * *}$ & $.648^{* * * *}$ & $.483^{* * * *}$ & $.344^{* * * *}$ \\
\hline SUB & & & $-.701^{* * * *}$ & $.583^{* * *}$ & $.391^{* * * *}$ & $.420^{* * * *}$ \\
\hline AoA & & & & $-.669^{* * * *}$ & $-.424^{* * * *}$ & $-.338^{* * * *}$ \\
\hline PRE & & & & & $.129^{*}$ & $.133^{*}$ \\
\hline LIT & & & & & & $.752^{* * * *}$ \\
\hline
\end{tabular}


Table 4 One-way analysis of variance statistics of the scores for the seven norms under the influences of the CYs' syntactic structures

\begin{tabular}{llll}
\hline & $F^{*}$ & $p$ & $R^{2}$ \\
\hline KNO & 2.98 & .007 & .050 \\
FAM & 7.76 & .000 & .120 \\
SUB & 5.85 & .000 & .093 \\
AoA & 1.32 & .249 & .023 \\
PRE & 1.74 & .110 & .030 \\
LIT & 6.41 & .000 & .101 \\
COM & 6.63 & .000 & .104 \\
\hline
\end{tabular}

$* d f_{\text {between }}=6, d f_{\text {within }}=343$

compositionality. However, the participants' evaluation scores for predictability were relatively weakly correlated with those for literality and compositionality. That is, compositionality and literality are not as strong predictors of a CY's overall meaning as are knowledge, familiarity, AoA, and subjective frequency.

In addition, the factor analysis revealed two main components, which accounted for $80.86 \%$ of the variances. Knowledge, familiarity, subjective frequency, AoA, and predictability mainly loaded onto the first factor, accounting for $61.95 \%$ of the variances, and compositionality and literality onto the second factor, accounting for $18.12 \%$ of the variances. Consistent with the discussions of the correlations, the first factor seem to reflect the participants' awareness of the CYs' noncompositional features, and the second factor their consciousness of the CYs' compositional characteristics.

\section{The CYs' syntactic structures}

Statistics from one-way analyses of variance (ANOVAs) of the participants' evaluation scores for the seven norms are shown in Table 4, with the CYs' differences in syntactic structure as the single variable. As is illustrated in Fig. 1, diversity existed between the scores for knowledge, familiarity,

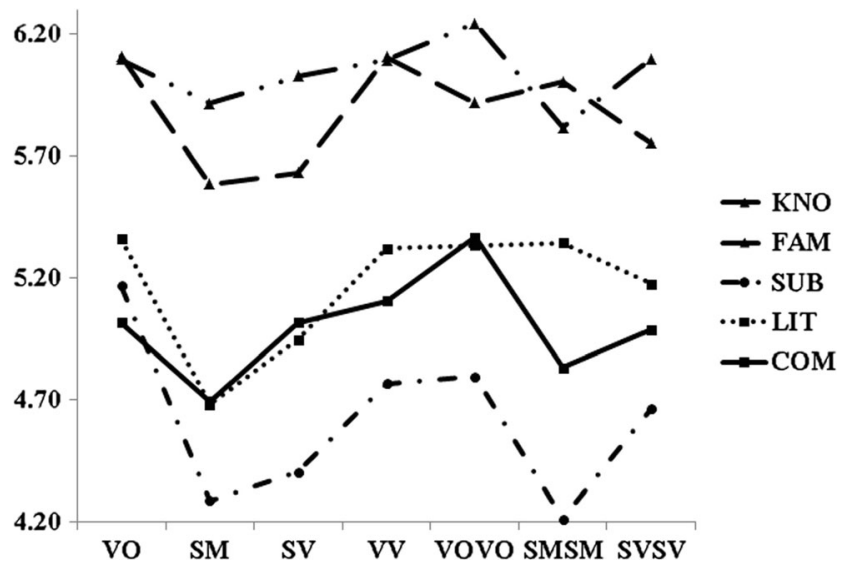

Fig. 1 Participants' scores for knowledge, familiarity, subjective frequency, literality, and compositionality under the influences of the CYs' syntactic structures subjective frequency, literality, and compositionality under the influences of the CYs' syntactic structures. Post-hoc least significant difference tests revealed significance differences between the CYs with different structures for each of the five norms (see Table 5).

Knowledge The CYs with an SM structure were significantly lower than VOVO CYs, and SMSM CYs were as well, in the evaluation scores for knowledge, suggesting that college students are more confident of knowing the meaning of and being able to verbally explain CYs with a VOVO composition than of doing either with SM or SMSM CYs.

Table 5 Significance levels for the pair-wise comparisons

\begin{tabular}{|c|c|c|c|}
\hline & FROM & $\mathrm{TO}$ & $p^{*}$ \\
\hline \multirow[t]{7}{*}{ LIT } & \multirow[t]{5}{*}{ SM } & VO & .001 \\
\hline & & VV & .001 \\
\hline & & VOVO & .001 \\
\hline & & SMSM & .001 \\
\hline & & SVSV & .001 \\
\hline & \multirow[t]{2}{*}{ SV } & VOVO & .005 \\
\hline & & SMSM & .006 \\
\hline \multirow[t]{8}{*}{$\mathrm{COM}$} & \multirow[t]{4}{*}{ SM } & VO & .006 \\
\hline & & SVSV & .006 \\
\hline & & VV & .001 \\
\hline & & VOVO & .001 \\
\hline & VO & VOVO & .003 \\
\hline & SVSV & VOVO & .003 \\
\hline & SMSM & VOVO & .001 \\
\hline & SVSV & VOVO & .001 \\
\hline \multirow[t]{10}{*}{ FAM } & \multirow[t]{4}{*}{$\mathrm{SM}$} & VO & .001 \\
\hline & & VV & .001 \\
\hline & & VOVO & .003 \\
\hline & & SMSM & .001 \\
\hline & \multirow[t]{4}{*}{ SV } & VO & .001 \\
\hline & & VV & .001 \\
\hline & & VOVO & .010 \\
\hline & & SMSM & .001 \\
\hline & \multirow[t]{2}{*}{ SVSV } & VO & .001 \\
\hline & & VV & .001 \\
\hline \multirow[t]{2}{*}{$\mathrm{KNO}$} & SM & VOVO & .004 \\
\hline & SMSM & VOVO & .001 \\
\hline \multirow[t]{5}{*}{ SUB } & SM & VO & .001 \\
\hline & SV & VO & .001 \\
\hline & \multirow[t]{3}{*}{ SMSM } & VO & .001 \\
\hline & & VV & .005 \\
\hline & & VOVO & .003 \\
\hline
\end{tabular}

The scores of the CYs of the structures in the FROM column were significantly lower than those in the TO column 
Familiarity In familiarity evaluation scores, the CYs with an SM structure were significantly lower than the CYs with VO, VV, VOVO, and SMSM structures; SV CYs were significantly lower than VO, VV, VOVO, and SMSM CYs; and SVSV CYs were significantly lower than VO and VV CYs. This suggests that CYs with SM and SV compositions are less familiar than those with VO, VV, VOVO, and SMSM structures, and that SVSV CYs are less familiar than those with VO and VV structures, to college students.

Subjective frequency The CYs with SM and SV structures were significantly lower than those with a VO structure, and the CYs with an SMSM composition were significantly lower than those with VO, VV, and VOVO compositions in the evaluation scores for subjective frequency. These results mainly indicate that college students most frequently encounter VO CYs, and much less frequently encounter those with SM, SV, and SMSM structures in daily life.

Literality The CYs with an SM structure were significantly lower than those with VO, VV, VOVO, SMSM, and SVSV structures, and the CYs with an SV composition were significantly lower than those with VOVO and SMSM compositions in evaluation scores for literality. This indicates that SM and SV CYs are more difficult to understand through the literal meanings of their component words in than are those with the other five structures, and that SM CYs seem even more so than SV CYs.

Compositionality The CYs with an SM structure were significantly lower than those with VO, SV, VV, and VOVO structures, and VOVO CYs were significantly higher than those with VO, SV, SMSM, and SVSV structures in compositionality evaluation scores. This mainly suggests that SM CYs are the most difficult to decompose, and that those with a VOVO structure are the most decomposable.

Explanations The participants' evaluation scores for AoA and predictability both tended to remain the same for the CYs of different syntactic structures. However, the CYs' syntactic structures had significant influences on the participants' evaluation scores for knowledge, familiarity, subjective frequency, literality, and compositionality, which requires explanation.
The participants had low scores for SM CYs in each of the five norms. Users may have a low degree of familiarity and understanding and a low frequency of encounter with CYs having an SM composition, which are difficult to understand merely through their constituent words and are unlikely to be decomposed in meaning. In other words, an SM CY that is unfamiliar to, not known by, or not frequently encountered by a user is not easy to comprehend or is undecomposable. Similarly, CYs with an SMSM structure also seem less likely to be known or encountered by users and to be less decomposable than those with VOVO and VO structures. Unlike SM CYs, however, SMSM CYs may not be less familiar to users and may be more likely to be comprehended just through their constituent characters, in comparison with CYs with a VOVO or VO structure. The differences between CYs with SM and SMSM structures seem to suggest that literality and compositionality are not the same, and that familiarity is different from knowledge or subjective frequency in indicating CYs' psycholinguistic characteristics.

CYs with an SV composition are less likely to be familiar to or encountered by users than are those with a VOVO or VO structure. Similar to SV CYs, in being less familiar to users than VOVO or VO CYs, SVSV CYs are dissimilar to their SV counterparts in not being less frequently encountered by users than VOVO or VO CYs. The difference between CYs with SV and SVSV compositions appears to indicate that familiarity is different from subjective frequency in nature.

Moreover, the changes in literality seem to have the same pattern as those in compositionality under the influence of CYs' syntactic structures, except that those with an SMSM structure were not significantly different from VOVO CYs in literality evaluations, but had significantly lower scores than VOVO CYs in compositionality evaluations.

One might intuitively feel that there are overlaps between knowledge, familiarity, and subjective frequency, or between literality and compositionality. However, the present study seems to provide a strong piece of evidence that neither knowledge, familiarity, and subjective frequency nor literality and compositionality can be taken as being the same.

\section{Implications}

The normative statistics and the interactions between the norms and the CYs' syntactic structures have significant 
implications for helping researchers do experimental studies into CYs' representations and comprehension. The apparent difference between CYs and idioms in other languages (Bonin et al., 2013; Libben \& Titone, 2008; Tabossi et al., 2011) in the correlations between literality and compositionality is in agreement with the findings of Zhang et al. (2013) that the meaning of an expression is more visually evident in Chinese than in an alphabetic language. Obviously, more research will be needed on the specific features of idioms in other languages than is available from the few languages in which normative studies have been conducted.

In the present study, the influence of patterns of CYs' syntactic structures on CYs' descriptive norms might indicate particular mechanisms for how CYs are represented and how they are comprehended. Liu, Li, Shu, Zhang, and Chen (2010); Zhang, Yang, Gu, and Ji (2013); and Liu and Cheung (2014) set good examples of experimental investigations into the cause-and-effect relation between CYs' syntactic structures and CYs' comprehension, but more work is needed in this line of research to help enhance the development of theories on idiom representation and idiom comprehension in general.

On the basis of the interactions between the five norms and the CYs' syntactic structures (see Fig. 1), one may conduct a series of experimental studies to help specify the nature of the superlemmas between the representations for idioms as wholes and those for their constituent words (Sprenger et al., 2006). Theoretical differences could be made available between twoand four-word CYs, and comparisons could also be made between two-word CYs with different structures and between four-word CYs with different structures, regarding how the connections are mediated between the conceptual representations for idioms as wholes and those for the constituent words.

In cognitive tasks of idiom recognition with and without sentential contexts, for example, comparisons could be made between participants' reaction times and/or event-related potentials to CYs with different syntactic structures, as are outlined in Table 6. Furthermore, regression analyses on participants' online performance with the norms as predictors could also be very fruitful in reflecting the norms' contributions to how the CYs of each syntactic structure are represented and/or comprehended.

Similarly, studies on the relations between the syntactic structures and normative features of idioms promise to yield interesting results in languages other than Chinese. Moreover, it seems to be clearly evidenced in the interactions between the syntactic structures and norms of the CYs (see Fig. 1) that familiarity is different from subjective frequency and that literality cannot be taken as being the
Table 6 Comparisons of CYs of different syntactic structures

\begin{tabular}{llll}
\hline 1 & SM & $\longleftrightarrow$ & SMSM \\
2 & SV & $\longleftarrow$ & SVSV \\
3 & VO & $\longleftarrow$ & VOVO \\
4 & SM & $\longleftarrow$ & SV \\
5 & VO & $\longleftarrow$ & VV \\
6 & SM & $\longleftarrow$ & VO \\
7 & SMSM & $\longleftarrow \longrightarrow$ & VOVO
\end{tabular}

Each line indicates a comparison of CYs of two different syntactic structures

same as compositionality. Both familiarity and subjective frequency and both literality and compositionality should be considered in normative studies of idioms, and probably in studies of words in general.

\section{Conclusion}

Our normative results for familiarity, knowledge, predictability, AoA, subjective frequency, literality, and compositionality among $350 \mathrm{CYs}$ with seven structures (VO, SM, SV, VV, VOVO, SMSM, and SVSV) seemed to support the hybrid view of idiom representation and comprehension. The influence of the CYs' syntactic structures on the descriptive norms did not have the same pattern for all variables. We concluded that CYs with an SM composition are less likely than VOVO CYs to be decomposable, to be recognized through their constituent words, or to be familiar to, known by, or encountered by users. CYs with an SMSM structure are also less likely than VOVO CYs to be decomposable or to be known or encountered by users. The present study provides an outline of how CYs' characteristics are intercorrelated and how their features interact with their syntactic structures, which can be used as a reference for further studies on idioms in Chinese. Empirical studies can investigate how the syntactic structure of a $\mathrm{CY}$ influences its representation and comprehension, so that the hybrid view on idiom representation and comprehension can be finely specified. However, the participants' homogeneity in age and background education in the present study might impose some limitations on the generalization of these findings. Moreover, similar surveys with a control group of two-character words would probably have made the results even more meaningful.

Acknowledgements This work was supported by the National Social Science Foundation of China under Grant 14ZDB155. 


\section{Appendix}

350 CYs of seven syntactic structures

CY

English translation

按图索䩀 by following up a clue

黯然失色 be outshone

百里挑一 one in a hundred

百年树人 it takes a hundred years to educate people

半路出家 switch to a job one was not trained for

遍地开花 blossom everywhere

涁涁有礼 be well-mannered

趁火打劫 stir up trouble to serve one's ends

乘虚而入 catch someone off guard

大家闺秀 girl from a good family

东山再起 stage a comeback

风流人物 an outstanding personage

风流韵事 love affair

好好先生 one who tries not to offend anyone

虎口余生 be snatched from the jaws of death

花花世界 community dazzling with a myriad temptations

黄金时代 golden age

恍然大悟 suddenly see the light

斤斤计较 haggle over every ounce

金字招牌 gold-lettered signboard

津津乐道 take delight in talking about

绝处逢生 be rescued unexpectedly from a desperate situation

慷慨陈词 speak in excitement

空洞无物 be devoid of content

空头支票 an empty promise

岁然不动 steadfastly stand one's ground

寥殄无几 few and far between

碌碌无为 lead a vain and humdrum life

绿林好汉 brigands

庞然大物 a huge monster

钦差大臣 imperial commissioner

倾盆大雨 torrential rain

如意算盘 indulge in wishful thinking

顺手牵羊 steal something in passing

死里逃生 have a close shave with death

跳梁小丑 a clumsy mischief-doer

纨绔子弟 a good-for-nothing from a wealthy family

蔚然成风 become a trend or a common practice

狭路相逢 come into unavoidable confrontation

相依为命 depend on each other for survival

悬崖勒马 pull back before it is too late

循循善诱 be good at teaching

羊肠小道 narrow meandering footpath

一网打尽 (of criminals etc.) round up the whole lot

衣锦夜行 parade with beautiful dress at night

以权谋私 abuse of power for personal gains 
蝇头小利 petty profits

与日俱增 be steadily on the increase

再生父母 great benefactor

中原逐鹿 fight among rivals for the throne

百废俱兴 full-scale reconstruction is underway

遍体鳞伤 be beaten black and blue

草木皆兵 be in a state of extreme nervousness

宠辱不惊 not be moved by (official) honour or disgrace

臭名昭著 of ill repute

寸丝不挂 be stark naked

大气磅礴 of great momentum

大势已去 the game is as good as lost

斗志昂扬 have plenty of fight in one

风云突变 a sudden change in the situation

福星高照 have a good luck

妇擩皆知 everyone knows about it

肝脑涂地 (in fighting for one's sovereign) lay down one's life

冠冕堂皇 high-sounding

花样翻新 retrofit

吉星高照 the lucky star shines bright

健步如飞 walk fast and vigorously

蛟龙得水 be happy like a dragon in water

金榜题名 succeed in a government examination

金屋藏娇 live with the young wife in a plush apartment

泾渭不分 fail to make a distinction between right and wrong

精神抖擞 in good spirits

狼烟四起 smoke signals rising on all sides

利欲熏心 be blinded by greed

蓬草生辉 Friends grace sb.'s house with their presence

品学兼优 excel in moral as academic performances

气势汹汹 with an aggressive posture

气息奄奄 at death's door

气宇轩昂 dignified and distinguished-looking

热血沸腾 burning with righteous indignation

人才辈出 talented people are produced by each generation

神色自若 look unperturbed

生灵涂炭 the people are plunged into an abyss of misery

声势浩大 an impressive display of power or influence

四大皆空 the sensuous world is illusory, all physical existence is vanity

涕泗滂沱 tears and mucus are flowing down rapidly

万马齐喑 the people's voices are stifled

万象更新 (with the advent of spring) all is fresh again

五彩缤纷 blazing with color

旭日东升 the sun is rising

学富五车 have read five cartloads of books

学海无涯 knowledge is boundless

血债累累 have a mountain of blood debts

夜郎自大 ignorant and boastful 
衣冠楚楚 be immaculately dressed

羽毛未丰 be young and inexperienced

众口难调 it's difficult to make everyone feel satisfied

众志成城 unity is strength

壮心不已 in high aspirations

壮志凌云 with soaring aspirations

搬弄是非 tell tales

别具慧眼 have a special insight understanding

别具匠心 have great originality

别具一格 have a distinctive (or unique) style

不成体统 mannerless

不落巢臼 be unconventional

不念旧恶 to forgive and forget

不省人事 be in a coma

不识大体 ignore the general interest

不识时务 show no understanding of the times

不务正业 not attend to one's proper duties or business

不遗余力 spare no effort

不远千里 make light of traveling a thousand li

不择手段 by hook or by crook

打破常规 break free from convention

大动干戈 get into a fight

大繁风景 dampen the spirits

大有文章 there's more to this than meets the eye

大展宏图 ride on the crest of success

颠倒是非 confuse right and wrong

独出心裁 be-original

顿开茅塞 suddenly see the light

各奔前程 each goes his own way

各持己见 each sticks to his own viewpoint

蛊惑人心 confuse and poison people's minds

好为人师 like to lecture to people

化为泡影 go up in smoke

荒无人烟 desolate and uninhabited

混淆黑白 confuse black and white

渐入佳境 get on soundings

捐弃前嫌 bury old grudges

夸大其词 exaggerate

浪迹天涯 rove all over the world

力排众议 override all objections

乱点鸳巻 misarrangement of matches

略知皮毛 have only a superficial understanding

三顾茅庐 call on someone repeatedly to enlist his help, etc.

三缄其口 with one's lips sealed

深入人心 sink deep into the hearts of the people

稳操胜券 certain or confident of winning

虚度年华 idle away one's time

腰缠万贯 wallow in money 
查无消息 have no news

查无音信 without any news for a long time

义结金兰 become sworn brothers [sisters]

勇冠三军 the bravest of the whole army

崭露头角 make a figure

支吾其词 speak haltingly or ambiguously (in order to hide the truth)

重蹈覆辙 follow the old road to ruin

坐收渔利 play off one against another

抱薪救火 do something to make the situation even worse

闭门造车 act blindly by divorcing oneself from reality

惩前毖后 learn from past mistakes to avoid future ones

出口成章 one's tongue is the pen of a ready writer

出奇制胜 defeat one's opponent by a surprise move

吹毛求疵 find fault with

得过且过 muddle along

得意忘形 forget oneself in one's excitement

反目成仇 fall out and become enemies

改过自新 mend one's ways

顾名思义 just as the name implies

过河拆桥 abandon one's benefactor once his help is not needed

过目成诵 have a photographic memory

画地为牢 restrict one's s activities to a designated area

画龙点睛 add the finishing touch

积劳成疾 fall ill from overwork

积土成山 many sand piled up will make a mountain

继往开来 carry forward the tradition and forge ahead into the future 见风使舵 have it both ways

VV

见贤思齐 Seeing another better than oneself, one tries to equal him.

见义勇为 never hesitate to do what is right

见异思迁 be inconstant

劫富济贫 rob the rich and help the poor

开门见山 come straight to the point

克敌制胜 gain mastery over the enemy

临阵磨枪 make preparations at the last moment

论资排辈 assign a job in accordance with qualifications and seniority

迷途知返 realize one's errors and mend one's ways

弃暗投明 to renounce a bad cause and join the camp of justice

浅尝辄止 dip into or make a cursory study of something

三思而行 think thrice before you act

杀一儆百 execute one person as a warning to others

舍己为人 sacrifice one's interests for others

随机应变 adapt oneself quickly to changing condition

投鼠忌器 fear the repercussions of certain actions

玩物丧志 excessive preoccupation with trivia saps the will

望梅止渴 console oneself with vain hopes

望洋兴叹 feel powerless and frustrated

委曲求全 make concessions in order to accommodate to a situation

信手拈来 (of writing) have the words at hand 
一蹶不振 unable to recover after a set-back

一劳永逸 accomplish something once to save future trouble

越珇代庖 go beyond one's duties to meddle with another's affairs

造谣惑众 cheat or mislead the people with rumours of one's own creation

斩草除根 stamp out the root of trouble

仗势欺人 bully others because one has power or powerful connections

知过必改 always correct an error when one becomes aware of it

助纣为虐 help the wicked perpetuate wicked deeds

自作自受 bear the ill consequence of one's own doings

做贼心虚 have a guilty conscience

不慌不忙 without hurry or bustle

残兵败将 remnants of a defeated army

沧海桑田 time brings great changes to the world

愁眉苦脸 pull a long face

唇枪舌剑 exchange heated words

粗心大意 be careless

大彻大悟 be greatly discerning and apprehending with

东张西望 glance this way and that

多谋善断 be resourceful and decisive

丰功伟绩 a great achievement

凤冠霞帔 chaplet and official robes

高视阔步 carry oneself proudly

鸿篇巨制 monumental work

胡作非为 act wildly against law and public opinion

尖嘴猴腮 have a mouth that sticks out and a chin like an ape's

兼收并蓄 to swallow anything and everything (uncritically)

娇生惯养 be pampered and spoiled

惊涛骇浪 terrifying waves

苦心孤诣 make extraordinary painstaking efforts

SMSM

老谋深算 be experienced and astute

漫山遍野 scattered over hill and dale

名存实亡 exist in name only

明眸皓齿 (usually of a woman) have beautiful features

能工巧匠 skillful craftsman

奴颜婢膝 servile

奇装异服 bizarre dress

起承转合 introduction, elucidation of the theme

千差万别 differ in thousands ways

轻举妄动 act recklessly

穷凶极恶 be extremely violent and wicked

如痴如醉 out of one's mind

三从四德 the three obediences and four virtues imposed on women

三皇五帝 Three August Ones and the Five Lords

三头六臂 super ability

深居简出 live a secluded life

生龙活虎 full of vigor and vitality

死去活来 (of crying, beating etc.) half dead

同舟共济 pull together in times of trouble 
突飞猛进 make phenomenal progress

文蹈武略 military expertise

闲情逸致 be in a leisurely and carefree mood

新仇旧恨 new hatred piled on the old

雄才大略 great talent and bold vision

血雨腥风 a foul wind and a rain of blood

一曝十寒 do something in fits and starts

优柔寡断 infirm of purpose

油嘴滑舌 a smooth tongue

远见卓识 foresight and sagacity

长治久安 a long and peaceful reign

真才实学 truly learned and genuinely talented

胆战心惊 be terror-stricken

弹尽粮绝 run out of ammunition and food

德高望重 enjoy high prestige and command universal respect

耳闻目睹 that which one sees and hears

风驰电掣 move at great speed

风吹雨打 exposed to the wind and rain

鬼使神差 a curious coincidence

国富民强 The nation is prosperous and the people are strong and powerful

海枯石烂 strong-willed and determined (often suggesting ever lasting love)

海阔天空 as boundless as the sea and sky

寒来暑往 with the passage of time

魂汼梦绕 be carried away into a region of dreams

酒足饭饱 feast to satiety

口快心直 blunt, outspoken, but honest

口是心非 say one thing and mean another

理直气壮 being self-confident on the strength of one's being right

柳暗花明 hard time change into better time

SVSV 龙盘虎踞 a strategically situated place

龙吟虎啸 dragons singing and tigers roaring

龙争虎斗 a fierce struggle between two evenly matched opponents

面红耳赤 be flushed with shame or anger

面黄肌瘦 emaciation with sallow complexion

名正言顺 perfectly justified

男尊女卑 Man is superior to woman

日新月异 never-ending changes and improvement

山盟海誓 lovers' vows

山穷水尽 be at the end of one's tether

身强力壮 strong

神出鬼没 (usually said of guerillas) appear and disappear mysteriously

势均力敌 evenly matched

天旋地转 very dizzy

天造地设 (of a couple) ideally matched

头昏脑涨 feel one's head swimming

头重脚轻 top-heavy

土崩瓦解 in total disintegration

心安理得 have peace of mind 
心狠手辣 heartless and cruel

心惊胆战 tremble with fear

心余力绌 one's ability falls short of one's wishes

心猿意马 indecisive or restless

烟消云散 vanish completely

言简意赅 brief and to the point

言听计从 always follow sb.'s advice

阴差阳错 a strange combination of circumstances

语重心长 be sincere and earnest

源远流长 have a long history

纸醉金迷 (a life of) luxury and dissipation

昼伏夜行 conceal oneself by day and march by night

自轻自贱 belittle oneself

罪大恶极 a heinous crime

安家立业 set up a home and establish a business

安居乐业 live and work in peace and contentment

安营扎寨 pitch a camp

卑躬屈膌 behave servilely or obsequiously

除暴安良 suppress the evil and pacify the good

传宗接代 to carry on the Stewart name

待人接物 the manner by which one deals with people

当家作主 wear the breeches

盗名欺世 gain fame by deceiving the public

妒贤䃚能 be jealous of the worthy and the able

断子绝孙 die sonless

发号施令 order people about

奉公守法 law-abiding

扶危济困 help those in danger and aid these in distress

改头换面 dish up the same old stuff in a new form

感恩戴德 be deeply grateful

顾此失彼 unable to attend to everything at one time

含冤负屈 suffer an unjust grievance

行云流水 a natural and flowing style of writing etc.

回肠荡气 (of music, poems etc.) inspirit and soul-stirring

建功立业 make contributions and start one's career

开天辟地 the first time in history

口传心授 oral teaching inspires true understanding

立身处世 the way of conducting oneself in society

弄巧成拙 outsmart oneself

弄虚作假 resort to deception

披肝沥胆 talk without reserve

铺天盖地 cover the sky and the earth

强词夺理 argue irrationally

如饥似渴 seek something eagerly

如胶似漆 be deeply attached to each other

丧心病狂 out of one's right mind, unscrupulous, perverse

审时度势 study and weigh the situation

谈天说地 chat about everything under the sun 
偷梁换柱 replace the beams and pillars (with inferior ones)

涂脂抹粉 doll up, whitewash

无牵无挂 carefree

无情无义 (saying) to have no emotion or sense of justice

嫌贫爱富 despise the poor and curry favor with the rich

兴师动众 mobilize one's forces

幸灾乐祸 rejoice in the calamity of others

嘘寒问暖 show a kind concern for another's comfort

循规蹈矩 observe all rules and regulations

扬眉吐气 feel proud and elated

忆苦思甜 call to mind past sufferings and think over the good times

游山玩水 make a sightseeing tour

有眼无珠 lack discerning power

斩钉截铁 speak or act with determination and courage

张牙舞爪 make threatening gestures like a beast of prey

震天动地 a loud noise rent the air

\begin{abstract}
Note. VO, SM, SV, and VV refer to chengyus (CYS) (Chinese four-character idioms) whose two two-character words form verb-object units, structures of modification, subject-verb units, and verb-verb units, respectively, and VOVO, SMSM, and SVSV CYS, the first and the second two one-character words of which both form VOs, SMs, and SVs, respectively
\end{abstract}

\section{References}

Bonin, P., Barry, C., Méot, A., \& Chalard, M. (2004). The influence of age of acquisition in word reading and other tasks: A never ending story? Journal of Memory and Language, 50, 456-476. doi:10. 1016/j.jml.2004.02.001

Bonin, P., Méot, A., \& Bugaiska, A. (2013). Norms and comprehension times for 305 French idiomatic expressions. Behavior Research Methods, 45, 1259-1271. doi:10.3758/s13428-013-0331-4

Cacciari, C., \& Tabossi, P. (1988). The comprehension of idioms. Journal of Memory and Language, 27, 668-683.

Caillies, S. (2009). Descriptions de 300 expressions idiomatiques: Familiarité, connaissance de leur signification, plausibilité littérale, “décomposabilité" et "prédictibilité.". L'Année Psychologique, 109, 463-508.

Caillies, S., \& Butcher, K. (2007). Comprehension of idiomatic expressions: Evidence for a new hybrid view. Metaphor and Symbol, 22, 79-108.

Caillies, S., \& Le Sourn-Bissaoui, S. (2008). Children's understanding of idioms and theory of mind development. Developmental Science, $11,703-711$.

Chen, G. (Ed.). (2009). Normal dictionary of Chinese Chengyu with full function. Changchun, China: Jilin (in Chinese).

Cronk, B. C., \& Schweigert, W. A. (1992). The comprehension of idioms: The effects of familiarity, literalness, and usage. Applied PsychoLinguistics, 13, 131-146.

Cronk, B. C., Susan, D., Lima, S. D., \& Schweigert, W. A. (1993). Idioms in sentences: Effects of frequency, literalness, and familiarity. Journal of Psycholinguistic Research, 22, 59-82.

Cutting, J. C., \& Bock, K. (1997). That's the way the cookie bounces: Syntactic and semantic components of experimentally elicited idiom blends. Memory \& Cognition, 25, 57-71.

Gibbs, R. W., \& Nayak, N. P. (1989). Psycholinguistic studies on the syntactic behavior of idioms. Cognitive Psychology, 21, 100-138.

Gibbs, R., Nayak, N., \& Cutting, C. (1989). How to kick the bucket and not decompose: Analyzability and idiom processing. Journal of Memory and Language, 28, 576-593.
Holsinger, E. (2013). Representing idioms: Syntactic and contextual effects on idiom processing. Language and Speech, 56, 373-394.

Johnston, R. A., \& Barry, C. (2006). Age of acquisition and lexical processing. Visual Cognition, 13, 789-845. doi:10.1080/ 13506280544000066

Konopka, A. E., \& Bock, K. (2009). Lexical or syntactic control of sentence formulation? Structural generalizations from idiom production. Cognitive Psychology, 58, 68-101.

Libben, M. R., \& Titone, D. A. (2008). The multidetermined nature of idiom processing. Memory \& Cognition, 36, 1103-1121. doi:10. 3758/MC.36.6.1103

Liu, L., \& Cheung, H. T. (2014). Acquisition of Chinese quadra-syllabic idiomatic expressions: Effects of semantic opacity and structural symmetry. First Language, 34, 336-353.

Liu, Y., Li, P., Shu, H., Zhang, Q., \& Chen, L. (2010). Structure and meaning in Chinese: An ERP study of idioms. Journal of Neurolinguistics, 23, 615-630.

Robert, P. R., Curt, B., Gary, D. S., \& Kathleen, E. M. (2001). Dissociation between syntactic and semantic processing during idiom comprehension. Journal of Experimental Psychology: Learning, Memory, and Cognition, 27, 1223-1237.

Sprenger, S. A., Levelt, W. J. M., \& Kempen, G. (2006). Lexical access during the production of idiomatic phrases. Journal of Memory and Language, 54, 161-184.

State Language Affairs Committee. (2008). Lexicon of common words in contemporary China. Beijing, China: The Commercial Press.

Swinney, D. A., \& Cutler, A. (1979). The access and processing of idiomatic expressions. Journal of Verbal Learning and Verbal Behavior, 18, 523-534.

Tabossi, P., Arduino, L., \& Fanari, R. (2011). Descriptive norms for 245 Italian idiomatic expressions. Behavior Research Methods, 43, 110 123. doi:10.3758/s13428-010-0018-Z

Titone, D. A., \& Connine, C. M. (1994a). Comprehension of idiomatic expressions: Effects of predictability and literality. Journal of Experimental Psychology: Learning, Memory, and Cognition, 20, 1126-1138. doi:10.1037/0278-7393.20.5.1126 
Titone, D. A., \& Connine, C. M. (1994b). Descriptive norms for 171 idiomatic expressions: Familiarity, compositionality, predictability, and literality. Metaphor and Symbolic Activity, 9, 247-270.

Titone, D. A., \& Connine, C. M. (1999). On the compositional and noncompositional nature of idiomatic expressions. Journal of Pragmatics, 31, 1655-1674.
Zhang, H., Yang, Y. M., Gu, J. X., \& Ji, F. (2013). ERP correlates of compositionality in Chinese idiom comprehension. Journal of Neurolinguistics, 26, 89-112.

Zhou, J. (2004). A study on the structure of Chinese lexicon (in Chinese: Hanyu cihui jiegoulun). Shanghai, China: Shanghai Dictionary Press. 